\title{
Research on Parameter Optimization of the Express Warehousing and Distribution System Based on the Box-Behnken Response Surface Methodology
}

\author{
Nan Zhao and Maochun Wang \\ School of Management, Guizhou University, Guiyang, Guizhou 550000, China \\ Correspondence should be addressed to Maochun Wang; mcwang@gzu.edu.cn
}

Received 7 August 2021; Accepted 27 August 2021; Published 13 September 2021

Academic Editor: Yi-Zhang Jiang

Copyright (c) 2021 Nan Zhao and Maochun Wang. This is an open access article distributed under the Creative Commons Attribution License, which permits unrestricted use, distribution, and reproduction in any medium, provided the original work is properly cited.

\begin{abstract}
The response surface method, which has not been applied in the field of logistics, is used to study the express storage and distribution system. The goal is to find out the key factors affecting "customer satisfaction" and "warehouse explosion" and determine the optimal parameters to minimize the operation time and congestion rate of the system. The Box-Behnken response surface method is used to optimize the factors such as sorting speed, distribution speed, sorting temporary storage capacity, and distribution temporary storage capacity in the system, and the logistics simulation software is used to verify the experiment. The predicted value is in good agreement with the measured value. The optimal parameters are sorting speed of $0.002 \mathrm{D} / \mathrm{PCS}$, distribution speed of $31 \mathrm{M} / D$, sorting temporary storage capacity of 502PCS, and distribution temporary storage capacity of 222PCS. It shows that the response surface method is feasible to optimize the parameters of express storage and distribution system and is helpful to further improve the logistics express service level.
\end{abstract}

\section{Introduction}

With the rapid development of information technology and the Internet plus, e-commerce is becoming the main force of China's economic and social development. Not only many domestic e-commerce enterprises but also foreign e-commerce giants have set foot in the Chinese market, making consumers face more choices. In this context, "customer satisfaction" has become an important indicator to measure the development of e-commerce enterprises. Whether e-commerce enterprises can quickly respond to and meet customer needs to the greatest extent determines the survival of the competitiveness of enterprises and development in the highly competitive market.

As a service industry of e-commerce, logistics industry is an important link between e-commerce enterprises and customers. This service is the most direct feeling of customers, with "visualization", and its service level directly affects customers' evaluation of e-commerce enterprises.
However, compared with the rapid development of e-commerce, the supporting warehousing and distribution operation, namely logistics express service, cannot fully keep up with its development. Especially when various platforms launch various preferential activities one after another, when the network transaction volume is huge and the package delivery volume is also huge, the "warehouse explosion event" often occurs, that is, in a short time, the pressure of the warehouse increases sharply and the distribution system also bears great pressure. In view of this phenomenon, by optimizing the express storage and distribution system, the "warehouse explosion event" can be reduced and the "customer satisfaction" can be improved.

At present, the research on the optimization of express storage and distribution at home and abroad is limited. Most scholars mainly use simulation or heuristic algorithms to study the optimization of storage and distribution. Li et al. [1] built a simulation model of express terminal logistics distribution to optimize the distribution path with the goal 
of minimizing the logistics distribution cost. Odkhishig et al. [2] introduced a simulation-based optimization method, which can improve the throughput and service level of the warehouse while keeping the number of workers unchanged. Jin [3] applied the genetic algorithm to study the pick-up and delivery separation express terminal distribution model with the goal of minimum cost. Mirosław kordos et al. [4] proposed a complete automatic solution based on the genetic algorithm to optimize the discrete product placement and order picking route in the warehouse.

Express warehousing and distribution system can simulate its composition, randomness and parameters through the simulation model, but the simulation operation is only the simulation of the real system and cannot get the optimal solution or the most satisfactory solution, so it needs to be combined with the optimization algorithm. The combination of the randomness of the system and the mathematical programming model will lead to a series of complex formulas, and the published models rarely consider the random factors. Response surface methodology (RSM) is a simulation optimization method. It can be easily combined with random factors and deterministic simulation problems. It is used to model and analyze the problem in which the response of interest is affected by multiple variables. Its ultimate purpose is to optimize the response. However, the literature on the application of response surface methodology in the field of logistics is basically blank. This paper studies the physical flow problem of express storage and distribution system based on response surface theory and discusses the feasibility of response surface method to study the logistics problem. The goal is to find out the key factors affecting "customer satisfaction" and "warehouse explosion" and determine the optimal parameters to minimize the operation time and congestion rate of the system.

\section{Construction of Simulation Model}

Starting from the "warehouse explosion event," this paper analyzes the relevant problems in the process of parcel distribution in various promotional activities and carries out simulation experiments on the sorting operation and subsequent delivery operation in the transit warehouse. In practice, the process of express warehousing and distribution is too cumbersome, and some operations do not affect the results of simulation experiments in this model. Therefore, the simulation model is simplified into the following links:

(1) The parcel is delivered to the express company and enters the area to be sorted for sorting.

(2) Input the package information and sort the packages intelligently according to different destinations.

(3) After picking, the packages are transferred to the waiting area for distribution.

(4) After the arrival of the delivery vehicle, the package shall be packaged and delivered according to the batch.
To be more in line with the actual model and not limit any other factors, only the impact of the storage capacity of the temporary storage area, the sorting operation of parcels and the later delivery operation on the logistics express service is considered, including the sorting speed, distribution speed, sorting temporary storage capacity, and distribution temporary storage capacity. The number $x$ of parcels transported per day is uniformly distributed. The purpose of this paper is to determine the optimal level of the combination of the above four factors, take consumer satisfaction as the main goal and reduce the congestion rate as the secondary goal, and use these two goals as the criteria to improve the logistics express service level in the whole warehouse explosion period.

To simulate the express warehousing and distribution process, the logistics simulation software Flexsim is used to establish the simulation model of warehousing and distribution, as shown in Figure 1. Consumer satisfaction is based on the running time of the model in the simulation, and the blockage rate is based on the proportion of the residence time of the package in the warehouse. Therefore, the model operation time and blockage rate are response variables.

\section{Response Surface Methodology}

The response surface methodology is based on a collection of sample points collected in a designated design space for a limited experimental design, and the fitted response variable replaces the real response surface. In engineering optimization design, the application of response surface methodology can not only get the relationship between response variables and factors but also get the optimization plan, that is, the optimal combination of factors so that the objective function can be optimized.

3.1. Response Surface Mathematical Model. In the response surface method, to obtain a mathematical model representing the relationship between factors and response variables, first-order and second-order response surface models in the form of linear or quadratic polynomial functions are often used to approximate. Usually a low-order polynomial can satisfy engineering application requirements; if the response surface has strong nonlinearity, then high-order polynomials are required. When considering the cross-effects between random variables, polynomials with crossterms can be used.

The basic form of the first-order response surface model is as follows:

$$
f(x)=\beta_{0}+\sum_{i=n}^{n}\left(\beta_{i} X_{i}\right) .
$$

The basic form of the second-order response surface model is as follows:

$$
f(x)=\beta_{0}+\sum_{i=n}^{n}\left(\beta_{i} X_{i}\right)+\sum_{i=1}^{n} \sum_{j \geq i}^{n}\left(\beta_{i j} X_{i} X_{j}\right)+\varepsilon .
$$




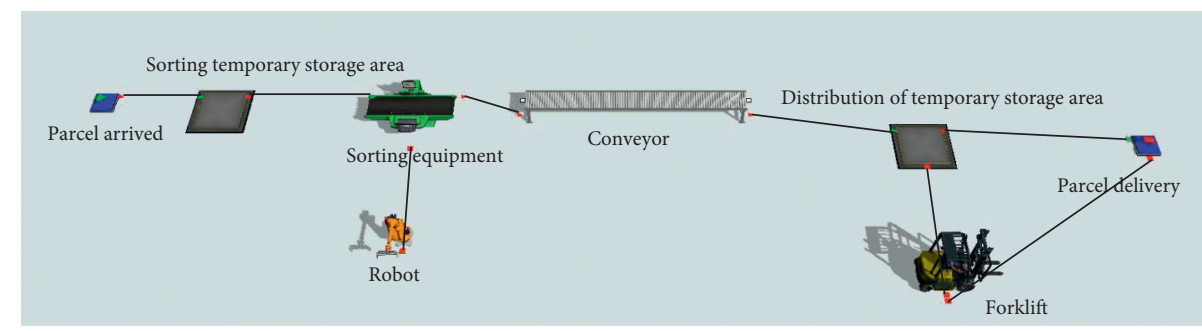

FIGURE 1: Simulation model of express warehousing and distribution system.

Among them, $x_{i}$ is the $i-$ th component of the $n$-dimensional independent variable $x ; \beta_{0}$ and $\beta_{i} \beta_{i j}$ are unknown parameters, which constitute the column vector $\beta$; and $\varepsilon$ is the error.

Usually in the process of calculation, the first-order model is used first, the purpose of which is to guide the experimenter along the path to improve the system to the optimal nearby area quickly and effectively. Once the optimal area is found, a more refined model can be used (for example, the second-order model). Perform analysis to determine the best position throughout. Estimate the regression coefficient of the regression equation using the least square method. Construct a polynomial response surface model.

To calculate the accuracy of the results, it is necessary to determine the accuracy of the fitting equation. It is usually determined in the form of variance.

$$
R^{2}=1-\frac{\sum_{i-1}^{N}\left(y_{i}-\tilde{y}_{i}\right)^{2}}{\sum_{i-1}^{N}\left(y_{i}-\bar{y}_{i}\right)^{2}} .
$$

where $N$ is the number of sample points, $y_{i}$ is the true response value, $\tilde{y}_{i}$ is the response value calculated by the response surface model, and $\bar{y}_{i}$ is the average value of the true response value.

The fitting accuracy of the model is usually evaluated by $R^{2}$ and the adjustment coefficient of determination Adj $R^{2}$. The closer $R^{2}$ and Adj $R^{2}$ are to 1 , the smaller is the error between the mathematical model and the original model and the higher is the fitting accuracy. However, if the design variables increase, the trend will be more for evaluation with Adj $R^{2}$.

3.2. Response Surface Experimental Design. There are many response surface experimental design methods. The commonly used methods are central composite design (CCD), D-optimal design (DoD), Box-Behnken design (BBD), and so on. [5-9]. Three key points should be paid attention to in the experimental design: determine the necessary experimental factors, determine the appropriate level of the selected experimental factors, and determine the reasonable level interval [10]. An appropriate experimental design is very important to obtain an ideal response surface model with the least calculation points [11].

BBD [12-15] is a commonly used the experimental design method of response surface methodology, which is suitable for optimization experiments with 2-5 factors. The
Box-Behnken design method takes 3 levels for each factor and encodes it with $(-1,0,1)$. The design arrangement takes 0 as the middle value, and the high value and low value correspond to +1 and -1 , respectively. With the same factors, the number of experiments designed by Box-Behnken is less and more economical, and the optimal level value solved by optimization will not exceed the range of the highest value, which is especially suitable for some experiments with special needs or safety requirements. According to the determined experimental factors and levels, the Box-Behnken response surface experimental design is carried out using design expert software to optimize the express storage and distribution system.

\section{Case Analysis}

This paper selects the parcel warehousing volume of the sorting center of an express company in November 2020 for analysis, as shown in Figure 2. Based on the above simulation model, the parameters of the model are set as follows: sorting speed [0.001 0.01], distribution speed [20 40], sorting temporary storage capacity [200 600], and distribution temporary storage capacity [200 400]. When setting the parameters of the simulation model, some data parameters are set by the actual data; In addition, through the continuous debugging of Flexsim, some parameters are obtained. Although these parameters are far from the actual data, they have strong expressiveness in the experiment and are feasible in theory.

4.1. Experimental Design and Results. The Box-Behnken response surface methodology was used to design the experiment with 4 factors and 3 levels, with sorting speed (A), distribution speed (B), sorting temporary storage capacity (C) and distribution temporary storage capacity $(D)$ as response factors and operation time and blockage rate as response values. The factors and levels are shown in Table 1, and the experimental scheme and results are shown in Table 2.

\subsection{Response Surface Analysis}

4.2.1. Regression Model and Analysis of Variance. Using Design-Expert12.0 software to regression fit the operation time $\left(Y_{1}\right)$ and blockage rate $\left(Y_{2}\right)$ in Table 2, the quadratic multiple regression model of operation time, blockage rate, and various factor variables can be obtained as follows: 


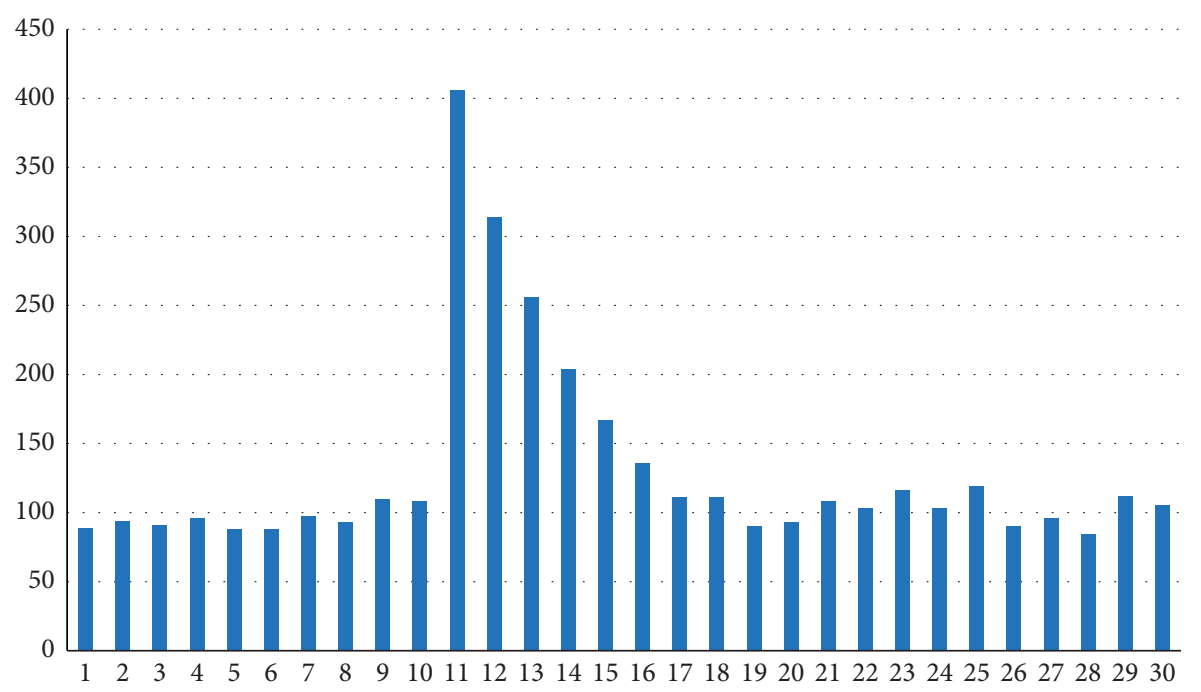

FIgURe 2: Parcel warehousing volume of sorting center of an express company in November 2020.

TABLE 1: Factors and levels.

\begin{tabular}{|c|c|c|c|c|}
\hline \multirow{2}{*}{ Factor } & \multirow{2}{*}{ Variable } & \multicolumn{3}{|c|}{ Level } \\
\hline & & -1 & 0 & 1 \\
\hline Sorting speed (D/PCS) & A & 0.001 & 0.0055 & 0.01 \\
\hline Delivery speed $(\mathrm{M} / D)$ & $\mathrm{B}$ & 20 & 30 & 40 \\
\hline Capacity of sorting temporary storage area (PCS) & $\mathrm{C}$ & 200 & 400 & 600 \\
\hline Distribution staging area capacity (PCS) & $\mathrm{D}$ & 200 & 300 & 400 \\
\hline
\end{tabular}

TABLE 2: Experimental scheme and results.

\begin{tabular}{|c|c|c|c|c|c|c|}
\hline Experiment number & A & $\mathrm{B}$ & $\mathrm{C}$ & $\mathrm{D}$ & Operation time $(D)$ & Blockage rate (\%) \\
\hline 1 & 0.001 & 20 & 400 & 300 & 32.12 & 12.4 \\
\hline 2 & 0.0055 & 30 & 200 & 400 & 30.59 & 29.6 \\
\hline 3 & 0.01 & 30 & 200 & 300 & 40.51 & 67.7 \\
\hline 4 & 0.01 & 30 & 600 & 300 & 40.51 & 53.8 \\
\hline 5 & 0.001 & 30 & 600 & 300 & 30.18 & 0 \\
\hline 6 & 0.01 & 30 & 400 & 200 & 40.51 & 60.8 \\
\hline 7 & 0.01 & 40 & 400 & 300 & 40.31 & 61.1 \\
\hline 8 & 0.001 & 30 & 200 & 300 & 30.18 & 9.1 \\
\hline 9 & 0.0055 & 40 & 200 & 300 & 30.43 & 29.7 \\
\hline 10 & 0.001 & 40 & 400 & 300 & 30.02 & 0 \\
\hline 11 & 0.0055 & 20 & 400 & 400 & 31.9 & 17.1 \\
\hline 12 & 0.0055 & 30 & 400 & 300 & 30.59 & 17.9 \\
\hline 13 & 0.0055 & 40 & 400 & 400 & 30.43 & 18 \\
\hline 14 & 0.0055 & 30 & 600 & 400 & 30.59 & 1.1 \\
\hline 15 & 0.0055 & 30 & 400 & 300 & 30.59 & 17.9 \\
\hline 16 & 0.0055 & 30 & 600 & 200 & 30.59 & 1.1 \\
\hline 17 & 0.0055 & 40 & 600 & 300 & 30.43 & 1.2 \\
\hline 18 & 0.0055 & 30 & 400 & 300 & 30.59 & 17.9 \\
\hline 19 & 0.0055 & 20 & 400 & 200 & 31.9 & 31 \\
\hline 20 & 0.0055 & 30 & 200 & 200 & 30.59 & 29.6 \\
\hline 21 & 0.0055 & 20 & 600 & 300 & 31.9 & 1.1 \\
\hline 22 & 0.0055 & 40 & 400 & 200 & 30.43 & 18 \\
\hline 23 & 0.0055 & 30 & 400 & 300 & 30.59 & 17.9 \\
\hline 24 & 0.0055 & 20 & 200 & 300 & 31.9 & 45.2 \\
\hline 25 & 0.001 & 30 & 400 & 200 & 30.18 & 1 \\
\hline 26 & 0.0055 & 30 & 400 & 300 & 30.59 & 17.9 \\
\hline 27 & 0.001 & 30 & 400 & 400 & 30.18 & 0 \\
\hline 28 & 0.01 & 20 & 400 & 300 & 40.43 & 60.9 \\
\hline 29 & 0.01 & 30 & 400 & 400 & 40.51 & 60.8 \\
\hline
\end{tabular}


TABLE 3: Results of analysis of variance.

\begin{tabular}{|c|c|c|c|c|c|c|}
\hline & Source & Sum of squares & $\mathrm{d} f$ & Mean square & $F$ value & $P$ value \\
\hline \multirow{19}{*}{ Operation time } & Model & 456.83 & 14 & 32.63 & 539.35 & $<0.0001$ \\
\hline & A & 299.20 & 1 & 299.20 & 4945.46 & $<0.0001$ \\
\hline & $B$ & 5.47 & 1 & 5.47 & 90.37 & $<0.0001$ \\
\hline & $C$ & 0.0000 & 1 & 0.0000 & 0.0000 & 1.0000 \\
\hline & $D$ & 0.0000 & 1 & 0.0000 & 0.0000 & 1.0000 \\
\hline & $\mathrm{AB}$ & 0.9801 & 1 & 0.9801 & 16.20 & 0.0013 \\
\hline & $\mathrm{AC}$ & 0.0000 & 1 & 0.0000 & 0.0000 & 1.0000 \\
\hline & $\mathrm{AD}$ & 0.0000 & 1 & 0.0000 & 0.0000 & 1.0000 \\
\hline & $\mathrm{BC}$ & 0.0000 & 1 & 0.0000 & 0.0000 & 1.0000 \\
\hline & $\mathrm{BD}$ & 0.0000 & 1 & 0.0000 & 0.0000 & 1.0000 \\
\hline & $\mathrm{CD}$ & 0.0000 & 1 & 0.0000 & 0.0000 & 1.0000 \\
\hline & $A^{2}$ & 142.58 & 1 & 142.58 & 2356.63 & $<0.0001$ \\
\hline & $B^{2}$ & 1.68 & 1 & 1.68 & 27.70 & 0.0001 \\
\hline & $C^{2}$ & 0.0072 & 1 & 0.0072 & 0.1191 & 0.7351 \\
\hline & $D^{2}$ & 0.0072 & 1 & 0.0072 & 0.1191 & 0.7351 \\
\hline & Residual & 0.8470 & 14 & 0.0605 & & \\
\hline & Lack of fit & 0.8470 & 10 & 0.0847 & & \\
\hline & Pure error & 0.0000 & 4 & 0.0000 & & \\
\hline & Cor total & 457.68 & 28 & & & \\
\hline \multirow{19}{*}{ Blockage rate } & Model & 13455.10 & 14 & 961.08 & 34.10 & $<0.0001$ \\
\hline & A & 9781.23 & 1 & 9781.23 & 347.04 & $<0.0001$ \\
\hline & $B$ & 131.34 & 1 & 131.34 & 4.66 & 0.0487 \\
\hline & $C$ & 1940.56 & 1 & 1940.56 & 68.85 & $<0.0001$ \\
\hline & $D$ & 18.50 & 1 & 18.50 & 0.6564 & 0.4314 \\
\hline & $\mathrm{AB}$ & 39.69 & 1 & 39.69 & 1.41 & 0.2551 \\
\hline & $\mathrm{AC}$ & 5.76 & 1 & 5.76 & 0.2044 & 0.6581 \\
\hline & $\mathrm{AD}$ & 0.2500 & 1 & 0.2500 & 0.0089 & 0.9263 \\
\hline & $\mathrm{BC}$ & 60.84 & 1 & 60.84 & 2.16 & 0.1639 \\
\hline & $\mathrm{BD}$ & 48.30 & 1 & 48.30 & 1.71 & 0.2116 \\
\hline & $\mathrm{CD}$ & 0.0000 & 1 & 0.0000 & 0.0000 & 1.0000 \\
\hline & $A^{2}$ & 1284.25 & 1 & 1284.25 & 45.57 & $<0.0001$ \\
\hline & $B^{2}$ & 43.29 & 1 & 43.29 & 1.54 & 0.2356 \\
\hline & $C^{2}$ & 3.45 & 1 & 3.45 & 0.1224 & 0.7317 \\
\hline & $D^{2}$ & 4.87 & 1 & 4.87 & 0.1729 & 0.6839 \\
\hline & Residual & 394.58 & 14 & 28.18 & & \\
\hline & Lack of fit & 394.58 & 10 & 39.46 & & \\
\hline & Pure error & 0.0000 & 4 & 0.0000 & & \\
\hline & Cor total & 13849.68 & 28 & & & \\
\hline
\end{tabular}

$$
\begin{aligned}
Y_{1}= & 30.59+4.99 A-0.6750 B+0.4950 A B+4.69 A^{2}+0.5083 B^{2}+0.0333 C^{2}+0.0333 D^{2}\left(R^{2}=0.9981 \mathrm{Adj} R^{2}=0.9963\right), \\
Y_{2}= & 17.90+28.55 A-3.31 B-12.72 C-1.24 D+3.15 A B-1.20 A C+0.2500 A D+3.90 B C+14.07 A^{2}+2.58 B^{2}-0.7292 C^{2} \\
& -0.8667 D^{2}\left(R^{2}=0.9715 \mathrm{Adj} R^{2}=0.9430\right) .
\end{aligned}
$$

Table 3 shows the results of analysis of variance, in which the correlation coefficient $R^{2}$ of multiple quadratic regression equation represents the difference between the predicted value and the experimental value, and its value is between 0 and 1 . When the value is 1 , it means that they are exactly the same. The smaller the difference between $R^{2}$ and $\operatorname{Adj} R^{2}$, the better the reliability of the fitted quadratic equation. The size of $P$ value indicates the significant influence of the model and various factors; $P<0.05$ indicates the significant influence of the model or parameters, and $P<0.01$ indicates the highly significant influence.
The correlation coefficient $R^{2}$ of the above two regression equations is greater than 0.9 , indicating that the predicted value has a good correlation with the experimental value. Therefore, this regression equation can be used to analyze and predict the optimized express storage and distribution system. In the two models, $R^{2}$ and Adj $R^{2}$ are 0.9981 and 0.9963 and 0.9715 and 0.9430 respectively, indicating that the two models have high reliability.

The variance analysis of the model shows that the $P$ values of the two models are $<0.0001$, indicating that it is very significant and the equation is meaningful. By analyzing the variance of the operation time model, it can be seen that 
the effect $P$ values of $\mathrm{A}, \mathrm{B}, \mathrm{AB}, \mathrm{A}^{2}$, and $\mathrm{B}^{2}$ are less than 0.01 , indicating that these five items have highly significant effects, while the $P$ values of other factor effects, interaction effects, or quadratic effects are large, indicating that $\mathrm{A}$ and $\mathrm{B}$ determine the response to a great extent, that is, sorting speed and distribution speed are the most critical factors affecting operation time. At the same time, $\mathrm{A}, \mathrm{C}$, and $\mathrm{A}^{2}$ in the blockage rate model are the model items with highly significant impact, B is the model item with significant impact, which has significant impact on the blockage rate, while the remaining items are nonsignificant items, which have no significant impact on the blockage rate.

4.2.2. Model Accuracy Verification. The residual is the difference between the observed value and the predicted value of the regression model. In the absence of experimental outliers, the residual should conform to the normal distribution. It can be seen from Figures 3 and 4 that the points in this figure are either on or near the straight line, indicating that the residual of this experiment is normally distributed and the model fitted by the response surface is accurate. On the contrary, if the points in the graph cannot form a straight line, it does not conform to the normal distribution.

Figure 5 shows the comparison between the measured value of operation time and the predicted result, and Figure 6 shows the comparison between the measured value of blockage rate and the predicted result. The $(X, Y)$ scatter diagram is drawn with the experimental sample data of operation time and blockage rate and the predicted result of the model as the abscissa and ordinate, respectively. Each scatter point is approximately distributed in a straight line and is located near the straight line $\mathrm{Y}=X$, indicating that the model fitting is good and the experimental model is reliable. It can be used for the prediction of practical experiments.

4.2.3. Response Surface and Contour Analysis. By looking at the results of analysis of variance, it can be inferred from the value of $f$ that within the selected experimental range, the influence of four factors on operation time is $A>B>C$ and $D$, and the interaction between factors $\mathrm{A}$ and $\mathrm{B}$ is the main interaction. The influence of four factors on the blockage rate is $A>C>B>D$, and the interaction between factor $\mathrm{A}$ and $\mathrm{C}$ is the main interaction. For the factors $\mathrm{A}$ and $\mathrm{B}$ and $\mathrm{A}$ and $\mathrm{C}$ that mainly affect the operation time and blockage rate model, the three-dimensional space and its contour map on the two-dimensional plane can intuitively reflect the interaction between the factors.

It can be seen from Figures 7 and 8 that the interaction between factors $\mathrm{A}$ and $\mathrm{B}$ and between factors $\mathrm{A}$ and $\mathrm{C}$ are significant. Figure 7 shows that the operation time first decreases and then increases with the increase of factors $A$ and $B$ under the interaction of factors $\mathrm{A}$ and $\mathrm{B}$; Figure 8 shows that the blockage rate increases with the increase of factors $\mathrm{A}$ and $\mathrm{C}$.

4.3. Response Surface Optimization Results and Verification. Based on the above response surface model analysis, the quadratic regression equation of the comprehensive index is

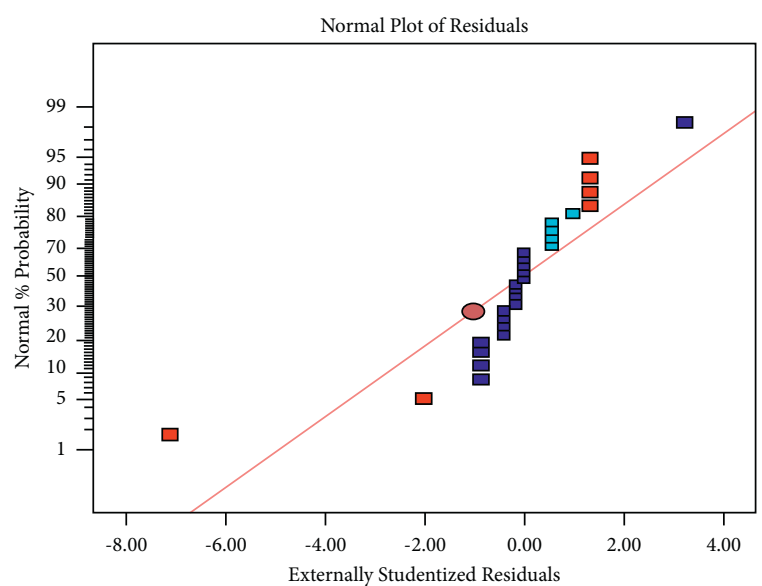

FIgURE 3: Normal plot of residuals (operation time).

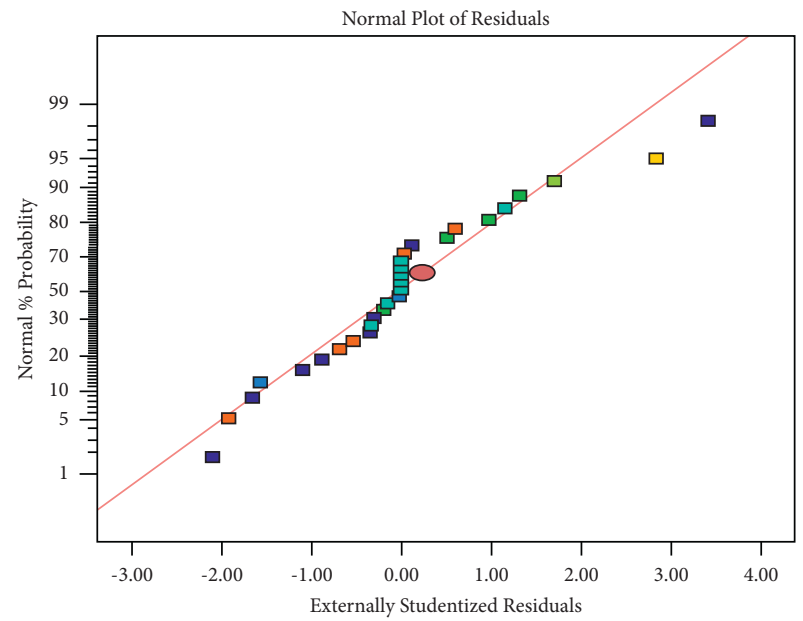

FIgURE 4: Normal plot of residuals (blockage rate).

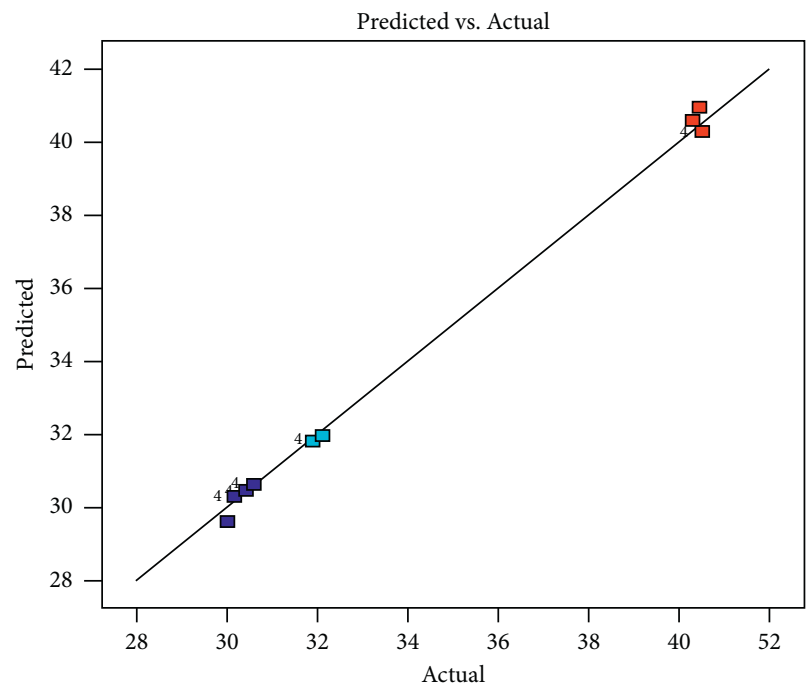

FIgURE 5: Predicted vs. actual of operation time.

solved using the Design-Expert12.0 software. The optimal parameters are A (sorting speed) $0.002 \mathrm{D} / \mathrm{PCS}, \mathrm{B}$ (distribution speed) $31.167 \mathrm{M} / D, \mathrm{C}$ (sorting temporary storage 


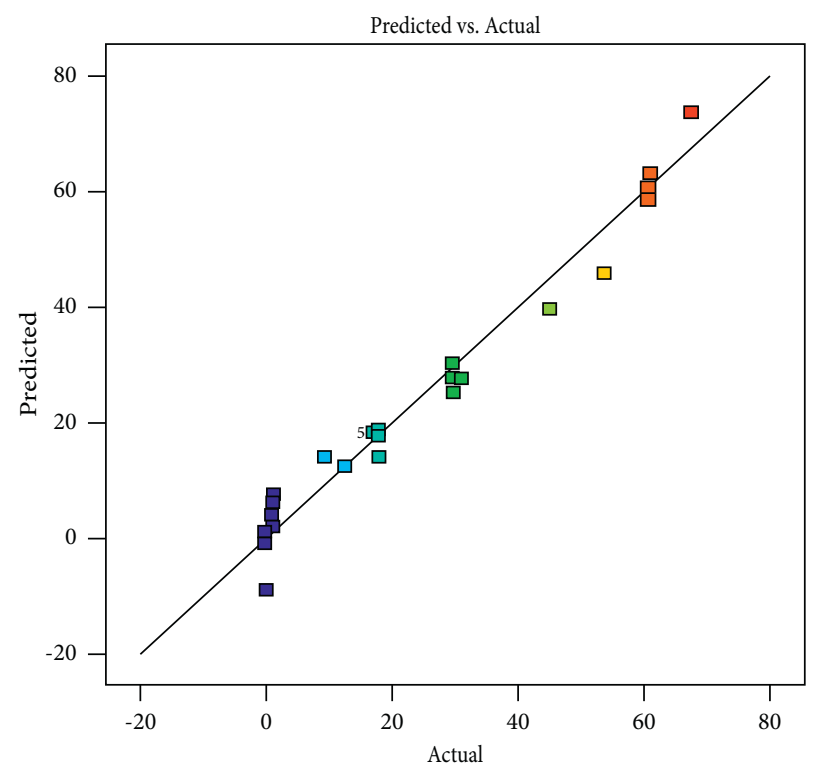

Figure 6: Predicted vs. actual blockage rate.
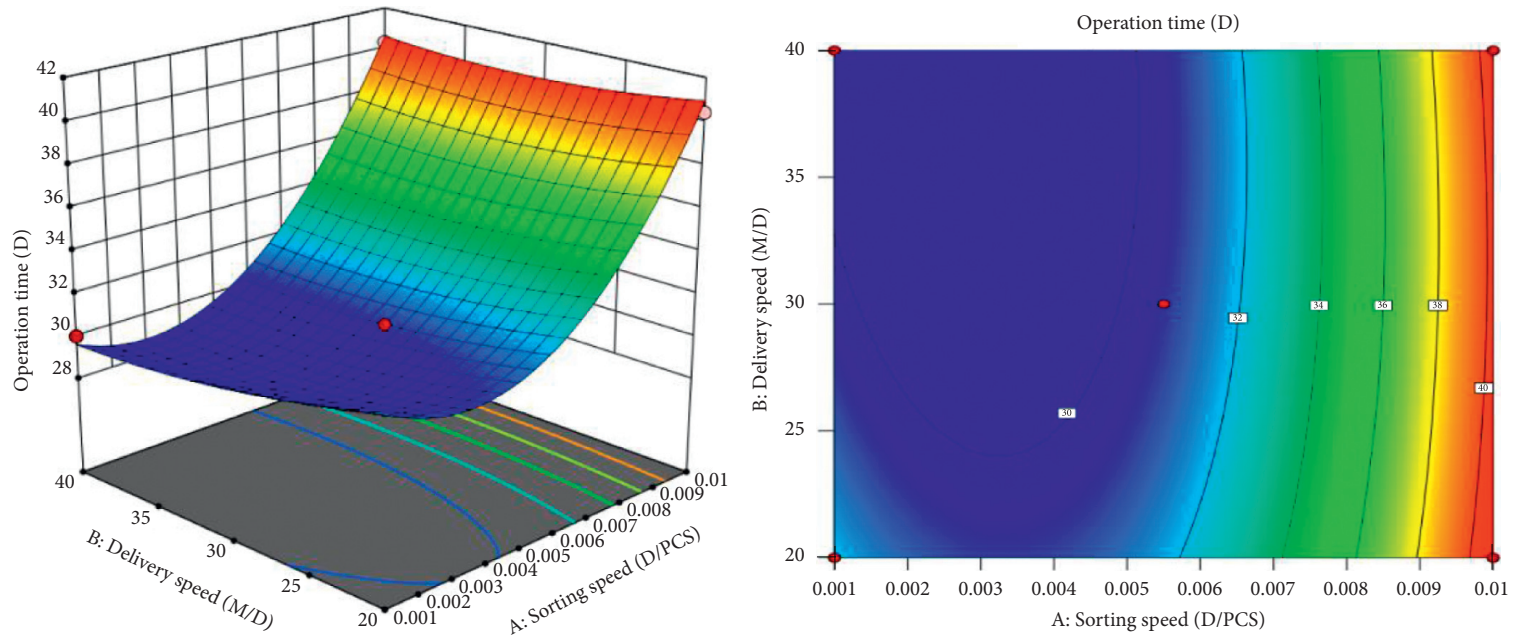

Figure 7: Response surface and contour of the interaction between sorting speed and distribution speed on operation time.
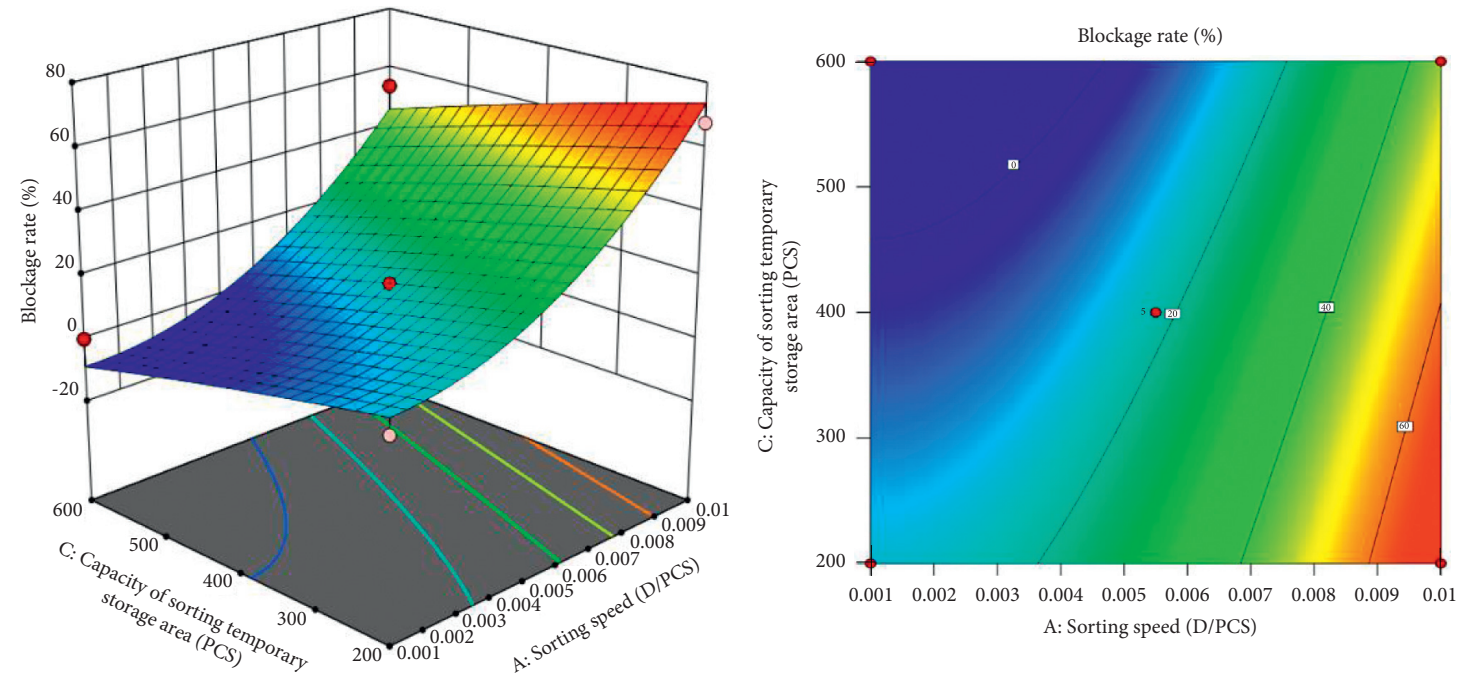

FIGURE 8: Response surface and contour diagram of the influence of the interaction between sorting speed and sorting temporary storage capacity on blockage rate. 
capacity) 502.350PCS, $D$ (distribution temporary storage capacity) $221.914 \mathrm{PCS}$, the operation time is $29.227 \mathrm{D}$, and the blocking rate is $-1.378 \%$, that is, there is no case that the package is detained in the warehouse.

To test the prediction results, it is necessary to verify the optimal parameters of the prediction. To facilitate the actual operation, some validation parameters are corrected to the distribution speed of $31 \mathrm{M} / D$, the sorting temporary storage capacity of 502PCS, and the distribution temporary storage capacity of 222PCS and the sorting speed remains unchanged at $0.002 \mathrm{D} / \mathrm{PCS}$. Running the logistics simulation model according to this parameter, the main target running time is $30.23 \mathrm{D}$. Compared with the predicted value of 29.227D, the deviation between the actual running time and the predicted running time is $3.32 \%$; the secondary target blockage rate was $0 \%$, and there was no blockage, which was consistent with the prediction effect.

In this study, the optimal parameters of the express storage and distribution system are sorting speed of $0.002 \mathrm{D} /$ PCS, distribution speed of $31 \mathrm{M} / D$, sorting temporary storage capacity of 502PCS, and distribution temporary storage capacity of 222PCS.

\section{Conclusion}

Owing to the difference of facilities and operating conditions, different simulation models of express warehousing and the distribution system will be produced. This paper studies the sorting operation and subsequent delivery operation in the transfer warehouse and the simulation model established under the ideal hypothesis state to determine the relevant parameters of the optimal express warehousing and distribution system to improve the consumer satisfaction index based on shortening working hours and reduce the congestion rate index based on the arrival congestion rate of packages.

The Box-Behnken response surface methodology is an optimization method integrating experimental design and mathematical modeling. It can effectively reduce the number of tests and shorten the experimental cycle. The analysis results are intuitive and clear, and the interaction between various factors can be investigated. The response surface method not only establishes the prediction model but also tests the adaptability of the model, the significance of the model and coefficient, analysis of variance and model diagnosis. In this paper, the parameters of express storage and distribution system are optimized by the Box-Behnken response surface methodology and the simulation experiment is carried out by Flexsim software. The optimization results and simulation results show that the deviation between the predicted value and the actual value is within $5 \%$, indicating that the correlation is good and the response surface methodology optimization of express storage and distribution system parameters is reasonable and feasible.

\section{Data Availability}

The labeled dataset used to support the findings of this study is available from the corresponding author upon request.

\section{Conflicts of Interest}

The authors declare no conflicts of interest.

\section{Acknowledgments}

This work was supported by the https://doi.org/10.13039/ 501100003459Guizhou University.

\section{References}

[1] N. Li, Y. Zhao, and D. Li, "Simulation and optimization of express terminal logistics distribution [J]," China management informatization, vol. 19, no. 18, pp. 75-77, 2016.

[2] O. Ganbold, K. Kundu, H. Li, and W. Zhang, "A simulationbased optimization method for warehouse worker assignment," Algorithms, vol. 13, no. 12, p. 326, 2020.

[3] Z. Jin, Analysis and Optimization of Express Terminal Distribution Mode, Beijing Jiaotong University, China, Beijing, 2017.

[4] M. Kordos, J. Boryczko, M. Blachnik, and S. Golak, "Optimization of warehouse operations with genetic algorithms," Applied Sciences, vol. 10, no. 14, p. 4817, 2020.

[5] L.-C. Zhao, Y. He, X. Deng et al., "Ultrasound-Assisted extraction of syringin from the bark of Ilex rotunda thumb using response surface methodology," International Journal of Molecular Sciences, vol. 13, no. 6, pp. 7607-7616, 2012.

[6] G. E. P. Box and K. B. Wilson, On the experimental attainment of optimum conditions Breakthroughs in statistics, Springer, New York, NY, USA, pp. 270-310, 1992.

[7] M. A. Bezerra, R. E. Santelli, E. P. Oliveira, L. S. Villar, and L. A. Escaleira, "Response surface methodology (RSM) as a tool for optimization in analytical chemistry," Talanta, vol. 76, no. 5, pp. 965-977, 2008.

[8] M. J. K. Bashir, H. A. Aziz, M. S. Yusoff, and M. N. Adlan, "Application of response surface methodology (RSM) for optimization of ammoniacal nitrogen removal from semiaerobic landfill leachate using ion exchange resin," Desalination, vol. 254, no. 1-3, pp. 154-161, 2010.

[9] M. M. Sarafraz, I. Tlili, Z. Tian, M. Bakouri, and M. R. Safaei, "Smart optimization of a thermosyphon heat pipe for an evacuated tube solar collector using response surface methodology (RSM)," Physica A: Statistical Mechanics and Its Applications, vol. 534, Article ID 122146, 2019.

[10] Z. Zong, M. Gao, and Z. Xia, "Finite element model validation of the continuous rigid frame bridge based on structural healthmonitoring partI:FE model updating based on the response surface method," [J].China Civil Engineering, vol. 44, no. 2, pp. 90-98, 2011.

[11] Q. Guo, L Zhang, and Q. Fei, "Response surface method and its experimental design for deterministic computer simulation," ACTA Aeronautica Et AstonauticaSinica, vol. 27, no. 1, pp. 55-61, 2006.

[12] S. L. C. Ferreira, R. E. Bruns, H. S. Ferreira et al., "BoxBehnken design: an alternative for the optimization of analytical methods," Analytica Chimica Acta, vol. 597, no. 2, pp. 179-186, 2007.

[13] J. Prakash Maran, S. Manikandan, K. Thirugnanasambandham, C. Vigna Nivetha, and R. Dinesh, "Box-Behnken design based statistical modeling for ultrasound-assisted extraction of corn silk polysaccharide," Carbohydrate Polymers, vol. 92, no. 1, pp. 604-611, 2013. 
[14] P. Tripathi, V. C. Srivastava, and A. Kumar, "Optimization of an azo dye batch adsorption parameters using Box-Behnken design,” Desalination, vol. 249, no. 3, pp. 1273-1279, 2009.

[15] G. Dwivedi and M. P. Sharma, "Application of Box-Behnken design in optimization of biodiesel yield from Pongamia oil and its stability analysis," Fuel, vol. 145, pp. 256-262, 2015. 